\title{
Preservation of Complex Microbial Communities in Serpentine-hosted Fracture Networks
}

\author{
J. ZALOUMis ${ }^{1}$, A. NEUBECK ${ }^{2}$, M. IVARSSON ${ }^{3}$, P.
} KELEMEN $^{4}$

${ }^{1}$ Arizona State University, School of Earth and Space

Exploration; jzaloumi@asu.edu

${ }^{2}$ Uppsala University, Department of Palaeobiology

${ }^{3}$ University of Southern Denmark, Department of Biology

${ }^{4}$ Columbia University, Department of Earth and

Environmental Science

Serpentinization is a geological process that involves the interaction of water and ultramafic rock, the chemical byproducts of which can serve as an energy source for chemolithoautotrophic microbial communities. Since their recognition as important geochemical sources of energy for life, serpentine deposits have become high-priority targets for directly investigating the existence and distribution of life in deep subsurface environments on Earth [1,2], and in exploring for the potential of extraterrestrial life on Mars where serpentine has been identified by remote sensing observations $[3,4]$.

When serpentinization reactions occur in the presence of dissolved $\mathrm{CO}_{2}$, the process can result in the precipitation of carbonate minerals such as magnesite, calcite, and dolomite. Notably, hydration and carbonation reactions associated with serpentinization results in an increase of the solid rock volume causing pressurization conditions that can lead to fracturing of the host rock $[5,6]$. Fractures created by this process, in addition to those created by local and regional tectonic processes, can function as conduits for water transport and may serve as habitable niche environments for microbial communities. As serpentinization proceeds along these fractures, so can the precipitation of carbonate minerals, which may eventually lead to fractures becoming completely sealed by carbonate minerals.

In the present study, we explore whether the precipitation of carbonate minerals within such fractures can serve as unique taphonomic windows to preserve evidence of subsurface microbial communities for geologic timescales. Here we report the detection of such fossilized communities within drill core samples of serpentine-hosted carbonate veins from the Samail Ophiolite in Oman.

[1] Chapelle et al. (2002) Nature 6869 312-315. [2] Onstott et al. (2019) Astrobiology 10 1230-1262. [3] Amador et al. (2018) Icarus 311 113-134. [4] Ehlmann et al. (2010) J Geophys Res 37 L06201. [5] Iyer et al. (2008) Earth and Planetary Science Letters 267 503-516 [5] Kelemen and Matter (2008) PNAS 45 17295-17300. 